\title{
E्Ereferão \\ Educação Integral e Escola de Tempo Integral em Goiânia
}

\author{
Helen Betane Ferreira' \\ Dilys Karen Rees' \\ 'Universidade Federal de Goiás (UFG), Goiânia/GO - Brasil
}

RESUMO - Educação Integral e Escola de Tempo Integral em Goiânia. O presente artigo visa analisar as concepções dos integrantes do corpo docente e administrativo de uma escola pública do município de Goiânia a respeito de educação integral e tempo integral. Trata-se de um estudo qualitativo de cunho etnográfico no qual foram utilizados os seguintes instrumentos de geração de dados: observação-participante, entrevistas, anotações de campo e leitura dos documentos oficiais que legislam sobre a educação integral e tempo integral no Brasil e no município de Goiânia. A análise dos domínios culturais, sugerida por Spradley (1980), revelou que o tempo integral não tem chegado às nossas escolas públicas de maneira planejada, prejudicando, assim, a efetivação da educação integral nessas instituições de ensino.

Palavras-chave: Educação Integral. Tempo Integral. Etnografia.

ABSTRACT - Integral Education and Fulltime Schools in Goiânia. This article aims at identifying the school staff's conceptions about integral education and fulltime schooling from a public school in Goiânia. It is a qualitative study based on ethnography in which the following instruments of generating data were used: participant observation, field notes, interviews, and the official documents that discuss integral education and fulltime schooling in Brazil and in Goiânia. The cultural domains analysis, suggested by Spradley (1980), revealed that the fulltime schooling model has not been well planned and established in our public schools, undermining the integral education effectiveness in these educational institutions. Keywords: Integral Education. Fulltime Schooling. Ethnography.

Educação \& Realidade, Porto Alegre, v. 40, n. 1, p. 229-251, jan./mar. 2015. 
Educação Integral e Escola de Tempo Integral em Goiânia

A educação é um processo social, é desenvolvimento. Não é a preparação para a vida, é a própria vida. John Dewey

\title{
Introdução
}

A educação brasileira vem se modificando ao longo dos anos na tentativa de acompanhar as constantes mudanças econômicas, políticas e sociais pelas quais nossa sociedade vem passando. É sabido, entretanto, que nem sempre a educação evolui a tempo e a contento a fim de se adequar aos novos paradigmas sociais e culturais que se apresentam. E é exatamente por isso que o trabalho no campo educacional constitui-se de um constante desafio para os profissionais que nele atuam.

O século XXI consolidou demandas que foram historicamente construídas em todas as esferas sociais, inclusive na educacional. A organização social atual exige uma escola multifuncional, com profissionais mais completos, integrais, que, além de dominar o conteúdo especializado, sejam preparados para lidar com os desafios da contemporaneidade. Esses profissionais devem estar capacitados para atuar na formação integral dos discentes, preparando-os para a vida em sociedade e para exercerem a cidadania em todas as suas vertentes.

É nesse novo paradigma social que o discurso de educar integralmente, de preparar os educandos, física, afetiva, cultural e cognitivamente ganha força e atinge todos os âmbitos da esfera política, concretizando-se nos documentos oficiais que regulamentam a educação no País. Assim, vemos as ideias do educador brasileiro Anísio Teixeira (1962) serem retomadas de forma contundente, pelo menos no discurso oficial. Para Anísio Teixeira, a efetivação da educação integral está subordinada à ampliação do tempo, sendo a escola de tempo integral a solução para melhorar a qualidade do ensino e atender às demandas da sociedade atual.

Contemporâneo de Anísio Teixeira, Gadotti (2009) contesta a premissa de que a educação integral está subordinada ao tempo integral. Para o autor, educar integralmente deve ser o objetivo primordial da escola, seja ela de tempo parcial ou integral. Contudo, a expansão do tempo integral no Brasil, na maioria das vezes, é uma tentativa de suprir necessidades sociais básicas não abarcadas pelo Estado.

\begin{abstract}
A educação integral é uma concepção da educação que não se confunde com o horário integral, o tempo integral ou a jornada integral. Alguns projetos de escola de tempo integral surgiram, como é o caso dos Cieps, para compensar deficiências do meio familiar, da própria sociedade. Os Cieps foram criados, tanto no estado quanto no município do Rio de Janeiro, nas décadas de 1980 e de 1990, como um 'Programa Especial de Educação'. [...] O projeto original dos Cieps previa até a construção de residências, na própria escola, para os alunos mais pobres e suas famílias, numa clara confusão entre o papel da escola e as
\end{abstract}


políticas sociais. A escola não pode fazer tudo o que a sociedade não está fazendo; ela não pode substituir todas as políticas sociais. A escola precisa cumprir bem a sua função de ensinar (Gadotti, 2009, p. 29-30).

Retomando os documentos oficiais, o Plano Nacional de Educação (PNE), aprovado pela Lei n. 10.172/2001, estabelece a obrigatoriedade do ensino fundamental, assegurando o acesso e a permanência de todas as crianças na escola até a conclusão dessa etapa. O documento ainda ratifica que o cumprimento dessa prioridade:

[...] inclui o necessário esforço dos sistemas de ensino para que todos obtenham a formação mínima para o exercício da cidadania e para o usufruto do patrimônio cultural da sociedade moderna. O processo pedagógico deverá ser adequado às necessidades dos alunos e corresponder a um ensino socialmente significativo. Prioridade de tempo integral para as crianças das camadas sociais mais necessitadas (Brasil - PNE, 2001, p. 35).

A Constituição Federal (1988), o Estatuto da Criança e do Adolescente (Lei 8.069/1990) e a Lei de Diretrizes e Bases da Educação Nacional (LDB) (Lei 9.394/1996) são documentos legais que estabelecem o direito à educação integral a todas as crianças e adolescentes do País. A LDB também preconiza a progressiva implantação do ensino em tempo integral nas instituições nacionais de ensino público:

Art. 34. A jornada escolar no ensino fundamental incluirá pelo menos quatro horas de trabalho efetivo em sala de aula, sendo progressivamente ampliado o período de permanência na escola. [...]§ $2^{\circ}$. O ensino fundamental será ministrado progressivamente em tempo integral, a critério dos sistemas de ensino (Brasil - LDB Lei 9.394/1996).

Corroborando esse raciocínio, o Programa para as Escolas Municipais com Atendimento em Tempo Integral da Secretaria Municipal de Ensino de Goiânia assim se posiciona:

[...] escola em Templo Integral se faz necessária não somente pelo fato de proporcionar um espaço no qual a criança e o adolescente permanecerão um período de tempo diário maior, mas, sobretudo, porque proporciona aos filhos da classe trabalhadora o acesso aos bens culturais (Goiânia - SME', 2009, p. 5).

Partindo do exposto, o presente trabalho pretende analisar como a relação educação integral e escola de tempo integral se dá em uma instituição de ensino da Rede Municipal de Goiânia, considerando os documentos oficiais que regem a implantação e o funcionamento das escolas em tempo integral no País, bem como as vozes daqueles inseridos e envolvidos nesse contexto.

Educação \& Realidade, Porto Alegre, v. 40, n. 1, p. 229-251, jan./mar. 2015. 231 
Educação Integral e Escola de Tempo Integral em Goiânia

\section{Educação Integral e Tempo Integral no Brasil}

A escola de tempo integral não se constitui de uma prática inovadora na história do Brasil. Segundo Freitas e Galter (2007), no período em que só uma parcela privilegiada da população tinha direito à educação, esta era realizada em tempo integral. Esse modelo de educação foi substituído pelo modelo que conhecemos hoje devido à necessidade de se ampliar o acesso de mais alunos à escola, como é explicitado na citação a seguir:

[...] transformações no modelo econômico brasileiro determinam as demandas por uma escola universal, reduz-se, então, a jornada diária, inclusive a própria duração da escola primária passa a ser questionada como uma das condições para poder estendê-la a toda a população (Freitas; Galter, 2007, p. 125).

Com a crescente industrialização brasileira, alavancada nos anos de 1920, houve a necessidade de preparar a população para essa nova realidade econômica, a qual demandava profissionais preparados para o trabalho. Assim, iniciou-se um movimento conhecido pela alcunha de Escola Nova, cuja filosofia pregava a universalização da escola pública, laica e gratuita. Esse movimento alcançou o ápice na década de 1930, principalmente após a divulgação, em 1932, do Manifesto da Escola Nova.

Integrante dessa corrente pedagógica, Anísio Teixeira defendia que a escola pública para todos deveria ser de tempo integral e municipalizada, visando atender aos interesses de cada comunidade. Essa escola que cuida desde a higiene e saúde das crianças até sua preparação para o exercício pleno da cidadania é apontada, pelo educador, como a solução para a educação primária brasileira. Na visão de Anísio Teixeira e outros educadores de sua geração, a escola em tempo integral também representa uma oportunidade de vida melhor para os socialmente marginalizados.

O pensamento de Anísio Teixeira foi influenciado pelas ideias de John Dewey, de quem foi aluno durante o curso de pós-graduação cursado nos Estados Unidos. Grande nome da chamada educação progressiva, Dewey advoga que um dos principais objetivos desse modelo educacional é educar a criança como um todo: física, emocional e intelectualmente. É dessa concepção que o termo educação integral se origina.

Pautado nos princípios do mestre Dewey, Anísio Teixeira funda, na década de 1950, o Centro Educacional Carneiro Ribeiro em Salvador, Bahia. No artigo publicado em 1959, o autor deixa claro os objetivos propostos para essa instituição educacional: formar para o trabalho e para a sociedade, dar as mínimas condições de alimentação e saúde, esporte, cultura e lazer. Para tanto, era preciso que a escola funcionasse em tempo integral. $\mathrm{O}$ autor assim explicita a organização da escola em questão: 
A escola primária seria dividida em dois setores, o da instrução propriamente dita, ou seja, da antiga escola de letras; e o da educação propriamente dita, ou seja, da escola ativa. No setor da instrução, manter-se-ia o trabalho convencional da classe, o ensino da leitura, escrita, aritmética e mais ciências físicas e sociais; e no setor da educação as atividades socializantes, a educação artística, o trabalho manual, as artes industriais e a educação física (Teixeira, 1962, p. 82).

Esse modelo de escola influenciou, nos anos de 1980, a implantação dos Centros Integrados de Educação Pública (CIEP's), no Rio de Janeiro, pelo professor Darcy Ribeiro. Estes eram unidades de período integral onde os alunos permaneciam por oito horas e recebiam quatro refeições diariamente. O objetivo desses centros era oferecer o ensino fundamental, constituído do currículo escolar formal, complementado com atividades esportivas, artísticas e recreativas diversificadas.

Desde então, várias tentativas, algumas bem sucedidas outras nem tanto, foram feitas no sentido de se implantar a concepção de educação integral em forma de escolas de tempo integral em vários estados brasileiros. Essa concepção de educação e organização escolar só chegou ao município de Goiânia em 2005, na gestão do então prefeito Iris Rezende Machado. Sob a responsabilidade da Secretaria Municipal de Educação, foram implantadas sete escolas de tempo integral em Goiânia. Segundo o Programa para as Escolas Municipais com Atendimento em Tempo Integral (2009), "[...] atualmente a REDE conta com quinze escolas que estão desenvolvendo o currículo com conteúdos básicos e com conteúdos diversificados com a ampliação do tempo escolar (Goiânia-SME, 2009, p. 9)"”.

O referido documento assim define a educação integral:

A educação integral refere-se ao cuidado que devemos ter com o nosso corpo (alimentação saudável, atividade física, descanso). Evidencia a necessidade de cuidarmos da emoção, da espiritualidade, da mente, dos valores para que possamos aprender a lidar com nossas contradições. A educação integral refere-se também aos cuidados que devemos ter com o outro para que possamos conviver e juntos edificar uma sociedade justa para todos (Goiânia - SME, 2009, p. 10).

O documento ainda enfatiza que a formação integral é um dos objetivos da proposta curricular da Rede Municipal de Ensino de Goiânia:

Um dos objetivos dos ciclos é garantir o direito do educando à sua formação integral, direito que se traduz na possibilidade de percorrer seu processo educativo, de adquirir e construir conhecimentos e de desenvolver potencialidades para interpretar a complexa realidade em que se vive, ao assumir a condição de sujeito interativo. A con-

Educação \& Realidade, Porto Alegre, v. 40, n. 1, p. 229-251, jan./mar. 2015. 233 
Educação Integral e Escola de Tempo Integral em Goiânia

cretização desse direito exige outra compreensão do que seja o processo de ensino-aprendizagem e de como ele se articula com a totalidade da formação humana (Goiânia SME, 2009, p. 61).

A REDE compartilha com Anísio Teixeira a premissa de que proporcionar ao aluno um tempo ampliado na escola é condição para uma educação de mais qualidade:

[...] a educação em tempo integral pode proporcionar aos filhos da classe trabalhadora o desenvolvimento integral porque propicia atividades complementares de formação como direito ao acesso a novas aprendizagens, contrariando, assim, a lógica do mercado, qual seja: quem tem acesso a determinados conhecimentos é quem pode pagar por eles (Goiânia-SME, 2009, p. 11).

A princípio, parece que a ideia de educação em tempo integral é uma unanimidade. Entretanto, há muitas críticas a esse modelo de organização escolar. Libâneo (2012), por exemplo, considera o tempo integral uma artimanha política que objetiva sobrepor a função social, de responsabilidade do Estado, à função prioritariamente pedagógica da escola. Isso porque a educação integral não precisa necessariamente se realizar na escola de tempo integral. Ademais, nem sempre a escola de tempo integral oferece uma educação integral, com ênfase na formação humana. Para o autor, o tempo integral visa muito mais diminuir a pobreza e a marginalidade do que contribuir efetivamente para uma educação integral de qualidade ${ }^{3}$.

Para Gadotti (2009), a expansão do tempo integral na escola pública deve-se ao fato de que a escola está assumindo novos encargos, sendo suas responsabilidades cada vez mais ampliadas. Respondendo por programas de proteção social (alimentação, atendimento médico-odontológico, dentre outros) que antes não eram considerados de sua alçada, a escola de tempo integral vai além da sala de aula, invadindo a área da assistência social. Segundo o autor, a escola não pode assumir o papel do Estado na condução de políticas sociais. A escola precisa, prioritariamente, cumprir bem a sua função de ensinar, de formar o educando integralmente.

Paro também se manifesta a respeito das críticas envolvendo a escola de tempo integral. Para ele, na perspectiva do atendimento escolar, o tempo integral coloca-se como um instrumento de fortalecimento da universalização da educação para as camadas populares. A esse respeito, Paro assim se posiciona:

\begin{abstract}
Às reivindicações e pressões populares por mais instrução, o Estado responde com propostas de escola de tempo integral, na qual o propósito principal não é a divulgação do saber sistematizado, mas a solução de problemas sociais localizados além dos limites da escola e que tem natureza não prioritariamente pedagógica (Paro, 1988, p. 14).
\end{abstract}


Acreditamos, pois, que tais críticas devem ser analisadas para que a proposta da escola em tempo integral não sirva para atender a outros interesses, além do compromisso com uma educação de qualidade. Desta feita, o que pretendemos investigar é a efetivação das ideias aqui apresentadas em uma escola de tempo integral da Rede Municipal de Ensino de Goiânia, bem como dar voz àqueles que atuam nesse contexto.

\section{Metodologia}

O presente trabalho constitui-se de um estudo de base etnográfica. Segundo André (2005), a etnografia, que etimologicamente significa descrição cultural, é um tipo de pesquisa desenvolvida por antropólogos para estudar a cultura e a sociedade. Para a autora, trata-se, pois, de um conjunto de técnicas utilizadas para coletar dados sobre os valores, os hábitos, as crenças, as práticas e os comportamentos de um determinado grupo social, resultando em um relato descritivo da comunidade pesquisada.

Apesar de não utilizar todos os pressupostos sugeridos pelos antropólogos, os estudos em educação fazem uso da linha filosófica do estudo etnográfico exatamente porque o mesmo possibilita a compreensão do grupo social escolar, as interações que nele ocorrem, os rituais, valores e práticas de comportamento vivenciadas nesse ambiente tão específico.

Em que medida se pode dizer que um trabalho pode ser caracterizado como do tipo etnográfico em educação? Em primeiro lugar, quando ele faz uso das técnicas que tradicionalmente são associadas à etnografia, ou seja, a observação participante, a entrevista intensiva e a análise de documentos. A observação é chamada de participante porque parte do princípio de que o pesquisador tem sempre um grau de interação com a situação estudada, afetando-a e sendo por ela afetado. As entrevistas têm a finalidade de aprofundar as questões e esclarecer os problemas observados. Os documentos são usados no sentido de contextualizar o fenômeno, explicitar suas vinculações mais profundas e completar as informações coletadas através de outras fontes (André, 2005, p. 28).

Para Spradley (1980), o etnógrafo deve não apenas observar os comportamentos e os estados emocionais do grupo social pesquisado, mas também refletir sobre o significado das ações e reações dos participantes em relação ao contexto no qual estão inseridos.

Em outras palavras, o autor - Spradley - procura mostrar que a investigação qualitativa de cunho etnográfico não se circunscreve apenas à visão ética, mas apoia-se também, na êmica. O termo êmico significa 'interno' (insider)

Educação \& Realidade, Porto Alegre, v. 40, n. 1, p. 229-251, jan./mar. 2015.

Disponível em: <http://www.ufrgs.br/edu_realidade> 
Educação Integral e Escola de Tempo Integral em Goiânia

e sugere que a interpretação de um fato ou valor cultural, seja de um indivíduo ou de um grupo, [...] deve levar em conta a verdade como ela é entendida pelas pessoas que vivenciam aquela determinada cultura. Essa perspectiva se alia à perspectiva ética, 'externa' (outsider) que tende a ser descritiva e que observa as estruturas comportamentais do grupo cultural em foco (Rees; Mello, 2011, p. 32).

Assim, a pesquisa etnográfica oferece oportunidades ricas de aprendizagem ao pesquisador. Ao assumir uma postura ética do contexto, o etnógrafo pode expandir a sua compreensão acerca dos eventos sociais ocorridos na cultura em questão, analisando esses eventos emicamente.

Segundo André “[...] o pesquisador é o instrumento principal na coleta e análise dos dados. Os dados são mediados pelo instrumento humano, o pesquisador" (André, 2005, p. 28). Assim, ao dar voz aos participantes, e a si mesmo enquanto observador participativo, o pesquisador estará interpretando o discurso desses participantes. Essa interpretação, por sua vez, está impregnada dos pré-conceitos e experiências de vida do pesquisador.

Mesmo integrando efetivamente o contexto da pesquisa, o etnógrafo deve procurar estranhar o familiar, ou seja, ver aquilo que lhe é tão corriqueiro com o olhar de um estranho. De acordo com Erickson (1984), a vida quotidiana é invisível, sendo que para torná-la visível, o pesquisador deve fazer perguntas do tipo por que isto é do jeito que é e não diferente? Segundo o autor, quando o etnógrafo questiona o evento, permite que o evento questione seus próprios pré-conceitos. Para Erickson, a etnografia “[...] não é um método de objetividade, mas de subjetividade disciplinada" (Erickson, 1984, p. 9). Spradley (1980) também sugere que o pesquisador deve estranhar o familiar através de uma série de perguntas descritivas, as quais procuram proporcionar uma melhor compreensão acerca do ambiente por ele tão conhecido, porém pouco notado.

Além das perguntas descritivas, há outros instrumentos disponíveis os quais o pesquisador pode utilizar. A observação detalhada e intensiva de um contexto, por um longo tempo, constitui um desses instrumentos. Esse tipo de observação permite ao estudioso tecer um panorama bastante fiel dos eventos culturais, bem como dos significados destes no ambiente observado. Esta é apenas uma das técnicas que caracterizam o método etnográfico de pesquisa. Vejamos outras:

Como método, a etnografia inclui as técnicas de observação, a observação-participante (observação e interação simultânea com os participantes do estudo), as entrevistas formais e informais com os participantes do estudo em situações reais, os registros em áudio ou vídeo para análises verticalizadas interações, coleta de documentos e materiais relevantes disponíveis no contexto de pesqui- 
sa, bem como outras técnicas necessárias para responder às perguntas de pesquisa de um determinado estudo (Watson-Gegeo, 2010, p. 527).

Por se tratar de um estudo de cunho etnográfico, foram utilizadas algumas dessas técnicas de geração $0^{5}$ de dados no presente trabalho: a observação-participante, entrevistas informais gravadas em áudio e análise de alguns documentos oficiais, como a Lei de Diretrizes e Bases da Educação, o Plano Nacional de Educação e o Programa para as Escolas com Atendimento em Tempo Integral da Rede Municipal de Ensino de Goiânia (versão preliminar). A partir desses instrumentos, procuramos, através da análise dos domínios culturais sugerida por Spradley (1980), interpretar os sentidos e os valores que os participantes atribuem às suas ações e às ações dos outros e quais papéis sociais são utilizados no momento em que as ações acontecem (Rees; Mello, 2011).

Os dados são interpretados seguindo os pressupostos da pesquisa etnográfica e o modelo de análise dos domínios culturais sugerido por Spradley (1980). Os domínios culturais são categorias de significados. Para o autor, toda cultura cria inúmeras categorias para classificar os elementos que dela fazem parte. Assim, os domínios, como categorias culturais, são constituídos de três elementos básicos: termo geral, termos incluídos e relação semântica. O termo geral refere-se ao domínio cultural a ser analisado. Os termos incluídos são as categorias menores encontradas dentro do domínio analisado. Por fim, a relação semântica faz a ligação entre os outros dois elementos do domínio cultural. A função da relação semântica é, pois, definir os termos incluídos, inserindo-os no domínio cultural.

\section{Análise e Discussão dos Dados}

Como mencionado anteriormente, nosso objetivo é identificar e analisar as concepções das participantes da pesquisa acerca de educação integral e escola de tempo integral. Duas professoras (uma professora de Educação Física e a outra Pedagoga), a então coordenadora pedagógica (aposentada desde junho de 2012) e a então diretora de uma escola Municipal de Tempo Integral foram ouvidas durante horas de entrevista.

A escolha dessas participantes deve-se ao fato de as mesmas pertencerem ao pequeno grupo de remanescentes do tempo parcial que acompanhou e vivenciou a implantação do tempo integral nesta escola. Isso porque, durante o período de transição (janeiro de 2008), muitos profissionais solicitaram remoção e foram lotados em outras instituições de ensino do município.

Quarenta profissionais, entre professores efetivos, substitutos, agentes educativos e corpo administrativo, compunham os turnos matutino, intermediário e vespertino à época da geração dos dados. Po-

Educação \& Realidade, Porto Alegre, v. 40, n. 1, p. 229-251, jan./mar. 2015.

Disponível em: <http://www.ufrgs.br/edu_realidade> 
rém, apenas seis permaneciam na escola o período todo (das 07h30min às 16h30min): as quatro participantes deste estudo, a secretária e uma agente educativa. A maioria trabalhava apenas um turno e completava a carga horária em outra escola da Rede Municipal de Ensino.

O processo de geração de dados foi relativamente longo. Ocorreu durante todo o ano de 2011, sendo que as entrevistas aconteceram entre os meses de agosto e dezembro. Durante as entrevistas, algumas questões serviram de fio condutor para que as participantes dissertassem à vontade sobre os temas nelas sugeridos, a saber:

1. Fale sobre a transição para o modelo atual de organização escolar (tempo integral).

2. Em sua opinião, quais as vantagens e/ ou desvantagens desse modelo?

3. O que você entende por educação integral?

4. Reflita e emita sua opinião sobre a afirmativa: a educação integral depende do tempo integral na escola?

5. Você considera que nossa escola oferece uma educação integral? Justifique.

É importante ressaltar que a escola em questão funcionou em período parcial de três turnos até o ano de 2007. Contudo, a partir de 2008, a instituição de ensino passou a funcionar em tempo integral durante o dia, atendendo aos alunos de 6 a 1lanos: Educação Infantil (do $1^{\circ}$ ao $3^{\circ}$ ano - Ciclo I) e Ensino Fundamental (do $4^{\circ}$ ao $6^{\circ}$ ano - Ciclo II); e à noite aos alunos da EJA (Educação de Jovens e Adultos). Os alunos do tempo integral eram divididos em seis turmas com aproximadamente trinta e cinco educandos em cada.

A seguir entraremos em contato com as vozes das participantes. A partir delas procuraremos identificar o que as mesmas pensam a respeito de educação integral, escola de tempo integral e tudo o que envolve essa relação. Por motivos didáticos tentamos separar cada tópico de discussão de acordo com o tema abordado pelas participantes. Entretanto, os temas são e, em alguns momentos, estão por demais imbricados, podendo se misturar ou até se repetirem.

Os alunos da escola de tempo integral tem a possibilidade de aprender xadrez, cantar, valorizar mais as artes. Mas a estrutura da escola deixa muito a desejar porque as crianças não tem um lugar pra almoçar, um lugar pra descanso. Deveria ter mais árvores, um gramado para elas poderem brincar, falta espaço (Pedagoga). 


\begin{tabular}{|c|c|c|}
\hline $\begin{array}{c}\text { Included Terms } \\
\text { (termos incluídos) }\end{array}$ & $\begin{array}{c}\text { Semantic Relationship } \\
\text { (relação semântica) }\end{array}$ & $\begin{array}{c}\text { Cover Terms } \\
\text { (termo geral) }\end{array}$ \\
\hline$X$ & é um lugar $Y$ \\
\hline $\begin{array}{c}\text { A escola de } \\
\text { tempo integral }\end{array}$ & é um lugar & $\begin{array}{c}\text { de se aprender xadrez, } \\
\text { música e arte }\end{array}$ \\
\hline
\end{tabular}

Como podemos perceber, a professora acredita que o acesso a atividades diversificadas só é possível na escola de tempo integral. Essa crença justifica-se pelo fato de que nas escolas de tempo parcial o tempo é destinado ao cumprimento das disciplinas obrigatórias do currículo. Atividades extras devem ser agendadas para outro tempo, fora do horário de aula. Assim, por ter a carga horária estendida, a escola de tempo integral possibilita o acesso das crianças a outros saberes, além daqueles oferecidos pelas disciplinas obrigatórias do currículo.

Borges (2012) ${ }^{6}$, parafraseando Anísio Teixeira, pontua que o currículo dever ser flexível, alternando atividades intelectuais com atividades práticas, como artes aplicadas, industriais e plásticas, além de jogos, recreação, ginástica, teatro, música e dança, distribuídas ao longo do dia. Contudo, esse modelo escolar exige mais planejamento das atividades, mais integração entre os profissionais envolvidos e, consequentemente, entre os conteúdos trabalhados, sejam eles de que áreas forem.

Segundo Borges (2012), o ideal é que se ofereça educação integral, na escola de tempo integral com currículo integrado. Esse currículo deve ser flexível e oportunizar ao aluno a participação em vários projetos, concomitantemente desenvolvidos, fazendo com que a permanência do educando na escola seja realmente proveitosa. Ainda de acordo com a autora, é preciso haver uma integração curricular entre as áreas do conhecimento e as oficinas para que a educação integral se materialize efetivamente. É necessário pensar na lógica da disciplina, na sua história e como o conteúdo desta se articula com a atualidade, integrando esses conteúdos às atividades e disciplinas complementares. Não há razão para a existência de tantas atividades se as mesmas não são relacionadas e integradas de forma a possibilitar a construção do conhecimento.

Como Borges (2012), acreditamos que é preciso relacionar, integrar conteúdos, disciplinas. Contudo, para tanto, é necessário que o professor, responsável por proporcionar ao aluno essa integração, esteja apto a fazê-lo. Para a autora, é imperativo que o professor tenha o conhecimento dos conteúdos específicos, bem como o conhecimento educacional, ou seja, a habilidade de lidar com os desafios diários da profissão. 
Educação Integral e Escola de Tempo Integral em Goiânia

A formação básica e continuada de professores é um tema amplo e complexo. Abordá-lo de forma aprofundada não é objetivo deste trabalho. Contudo, tal tema permeia a fala das participantes. Isso porque, segundo as mesmas, não houve a preocupação prévia, por parte da Secretaria Municipal de Educação, em preparar, formar os profissionais para atuar nesse novo modelo de organização escolar.

Quando entramos de férias em dezembro de 2007, a escola era de ensino regular, normalzinha, matutino e vespertino. Quando foi janeiro, $n a$ semana de planejamento, aí falaram pra nós que a escola tinha virado de tempo integral, assim de uma hora pra outra. Nossa escola estava em vias de ser fechada porque não tinha quantitativo de aluno. A Secretaria veio, fez entrevista com todos nós e disse que três sábados por mês a gente ia ter que fazer curso sem acréscimo na remuneração. Daí perdemos um monte de profissionais que assustaram com a ideia do tempo integral e pediram remoção. Alguns professores ameaçaram entrar na justiça por causa desses sábados daí o curso acabou sem nem ter começado direito. Ninguém sabia o que fazer nem como fazer (Coordenadora pedagógica).

A diretora da escola ratifica a fala da coordenadora pedagógica, enfatizando a insegurança de professores e alunos com relação à implantação do novo modelo de funcionamento da instituição de ensino.

A escola foi fundada em 1974 e no final do ano de 2007, nos últimos dias, foi informada que no ano seguinte ia mudar. Não é fácil, não foi fácil e continua não sendo fácil. Ninguém estava preparado para essa mudança. Ficamos muito perdidos com relação à rotina da escola. Os alunos também tiveram dificuldade para adaptar até porque eles não sentiam segurança da nossa parte também (Diretora).

No começo foi horrível. Tinha menino que ficava com a mochila nas costas o tempo todo querendo ir embora. Os alunos não aguentavam ficar na escola o dia inteiro. Os professores não sabiam o que fazer com a indisciplina, que era insuportável. Se hoje já é difícil, naquela época era impossível. Tínhamos menos profissionais ainda do que tem hoje (Coordenadora pedagógica).

Os excertos supracitados nos levam a visualizar como foi conturbado o processo de transição para funcionários e alunos. A ausência de preparação causou uma desestabilização do ambiente, com alunos e professores, principalmente, perdidos sem saberem exatamente como agir. Não acreditamos que mudanças bruscas possam trazer benefícios. Talvez se a escola tivesse sido avisada com alguns meses de antecedência, professores e funcionários tivessem passado por um período de orientação, tanto prévia quanto durante os primeiros meses do processo de transição, este poderia ter sido menos sofrido para todos. Enfim, a nós parece que faltou o tão falado, exaltado e defendido por educadores, pedagogos e afins: planejamento.

Ao serem questionadas se a escola oferece educação integral aos alunos, obtivemos respostas variadas: 
Na minha opinião, a escola não oferece ainda uma educação integral ao aluno justamente por causa desse ponto aí que é a estrutura da escola (Pedagoga).

\begin{tabular}{|c|c|c|}
\hline $\begin{array}{c}\text { Included Terms } \\
\text { (termos incluídos) }\end{array}$ & $\begin{array}{c}\text { Semantic Relationship } \\
\text { (relação semântica) }\end{array}$ & $\begin{array}{c}\text { Cover Terms } \\
\text { (termo geral) }\end{array}$ \\
\hline$X$ & é um meio & de $Y$ \\
\hline$\bullet \begin{array}{c}\text { Estrutura } \\
\text { adequada }\end{array}$ & é um meio & $\begin{array}{c}\text { de a escola oferecer } \\
\text { educação integral }\end{array}$ \\
\hline
\end{tabular}

De acordo com a professora, a estrutura física da escola é condição sine qua non para a realização da educação integral, ou seja, a estrutura inadequada impede a prática da educação integral. Como aponta Borges (2012), a estrutura física e espacial é sim um fator importante para o sucesso do funcionamento da escola de tempo integral, visto que a variedade e a quantidade de atividades exigem mais salas de aula e espaços apropriados. Contudo, não é o fator primeiro para a concretização da educação integral. Esta depende, primeiramente, de profissionais preparados, qualificados, comprometidos e de uma estrutura física básica que atenda às especificidades de uma instituição que funcione em tempo integral.

Voltamos à questão da formação. Há que se enfatizar aqui a necessidade de oferecer formação continuada aos profissionais, bem como oportunizar a participação de todos. Vejamos o que a pedagoga tem a dizer a esse respeito:

O ano passado tinha um curso para os professores de escolas de tempo integral, oferecido pela Secretaria de Educação. Era aos sábados e, como a gente já trabalha muitos sábados, pouca gente animou a fazer. Esse ano não teve. A Secretaria oferece cursos, mas é em horário contrário ou à noite. É muito cansativo, pois a maioria trabalha dois às vezes três turnos. Eu acho que deveria voltar os cursos no horário de trabalho. Ou dispensar os alunos uma vez por mês que seja para que todos os profissionais da escola possam ter a chance de participar de um curso desses. Quem trabalha em escola de tempo integral não pode fazer curso no horário de trabalho, mas é um trabalho! Não é valorizado essa parte. A gente tem que trabalhar na escola de tempo integral, dar aula e pronto (Pedagoga).

Concordamos com Borges quando esta afirma que "[...] uma Educação Integral que se preze começa com a valorização dos profissionais, profissionais preparados e com formação específica para cada área de atuação" (Borges, 2012, comunicação verbal). Giolo compartilha da opinião de Borges e acrescenta: "Na esfera dos direitos dos professores, além de uma instituição regrada e bem equipada e de uma comunidade escolar atuante, é preciso adicionar o da formação continuada. O professor precisa estudar" (Giolo, 2012, p. 103).

A seguir, outras opiniões acerca da questão: nossa escola oferece uma educação integral? 
Educação Integral e Escola de Tempo Integral em Goiânia

Eu acredito que nossa escola oferece uma educação integral. Nosso IDEB (Índice de Desenvolvimento da Educação Básica) só tá crescendo. Na provinha Brasil nossos alunos saíram bem. Nossos alunos estão preparados. Professor que não é comprometido não fica na nossa escola, porque o grupo é comprometido. Ninguém finge que dá aula. Eu acredito que a gente tá trabalhando de forma integral com esses meninos (Coordenadora pedagógica).

\begin{tabular}{|c|c|c|}
\hline $\begin{array}{c}\text { Included Terms } \\
\text { (termos incluídos) }\end{array}$ & $\begin{array}{c}\text { Semantic Relationship } \\
\text { (relação semântica) }\end{array}$ & $\begin{array}{c}\text { Cover Terms } \\
\text { (termo geral) }\end{array}$ \\
\hline$X$ & é resultado & $Y$ \\
\hline$\bullet \quad \begin{array}{c}\text { Boas notas } \\
\text { nas avaliações } \\
\text { nacionais }\end{array}$ & são resultado & $\begin{array}{c}\text { de uma educação } \\
\text { integral }\end{array}$ \\
\hline
\end{tabular}

Se é de tempo integral a gente acredita que está trabalhando de forma integral o aluno e infelizmente a estrutura e falta de profissional, falta assim, não é falta, tem que ter mais profissionais... Então aí não dá pra ter essa educação integral. A escola de tempo integral tem que ter mais pessoas para dar essa educação integral para os alunos. Ainda tem muito que melhorar, mas muito mesmo. Ainda esbarra na estrutura e na falta de profissional (Professora de Educação Física).

\begin{tabular}{|c|c|c|}
\hline $\begin{array}{c}\text { Included Terms } \\
\text { (termos incluídos) }\end{array}$ & $\begin{array}{c}\text { Semantic Relationship } \\
\text { (relação semântica) }\end{array}$ & $\begin{array}{c}\text { Cover Terms } \\
\text { (termo geral) }\end{array}$ \\
\hline$X$ & é uma atribuição & de $Y$ \\
\hline$\bullet \quad \begin{array}{c}\text { Educação } \\
\text { integral }\end{array}$ & é uma atribuição & $\begin{array}{c}\text { da escola de tempo } \\
\text { integral }\end{array}$ \\
\hline
\end{tabular}

Para a coordenadora pedagógica, o bom desempenho nas avaliações nacionais é resultado da educação integral oferecida pela escola. A mesma considera os alunos preparados, sendo que esse sucesso é consequência do comprometimento dos professores.

Corroboramos a ideia de que bons resultados nas avaliações nacionais é algo muito positivo, pois estes podem trazer benefícios materiais, financeiros e humanos para as instituições que se destacam. Contudo, atingir boas notas nessas avaliações não significa que a escola consegue oferecer a tão almejada educação integral, pois nesta subjaz uma concepção de ser humano que transcende as concepções redutoras que ainda estão em voga na Educação (Borges, 2012). A educação integral ultrapassa o nível da instrução, procurando atingir o ser humano em todas as suas nuanças e potencialidades. Ademais, as avaliações nacionais procuram medir a qualidade do ensino-aprendizagem, mas não conseguem medir o nível de Educação que os educandos estão recebendo, para além da instrução.

Na seleção e organização dos fundamentos que sustentam a educação integral, é preciso atentar para a distinção entre os processos de educação como ato inteiro de cuidado 
necessário ao pleno desenvolvimento da pessoa ou como mero ato de ensino ou de instrução (Morin, 2001, p. 10).

Distinguir os processos de educação não significa priorizar um ou outro, mas ter a certeza de que ambos se complementam para formar o que chamamos de Educação Integral.

A professora de Educação Física relaciona a educação integral com o fato de a escola ser de tempo integral. Primeiro ela afirma que, sendo a escola de tempo integral, logo a educação integral é oferecida. Aqui os termos escola de tempo integral e educação integral são usados de modo interdependente, como se ambos só pudessem existir juntos. Depois, a professora atribui à falta de estrutura física da instituição e à falta de profissionais a impossibilidade de se oferecer uma educação integral aos alunos.

Na minha opinião, educar integralmente é dispor ao aluno várias ferramentas, e que ele possa escolher quais seriam as de seu interesse, e essas ferramentas desenvolvessem a sua capacidade além dos conteúdos obrigatórios. Ou seja, o aluno desenvolver outras habilidades. Atividades interessantes no horário livre. Deveria ter uma piscina na escola para que eles pudessem fazer uma aula de natação que é uma habilidade que muita criança aqui ia desenvolver (Pedagoga).

Um ponto interessante levantado pela fala da pedagoga: a escolha do aluno. Este deveria escolher a atividade de seu interesse para ser realizada em seu tempo livre. O Manifesto dos Pioneiros da Escola Nova (1932), do qual Anísio Teixeira participou, já defendia que o processo de aprendizagem deveria ser mais criativo e menos rígido e que os interesses dos alunos deveriam ser considerados. Contudo, segundo a fala da professora, e nossa própria visão êmica, os alunos dessa escola não tem direito de escolha, nem tem uma gama de atividades a serem escolhidas para atender a seus interesses e / ou desenvolver suas habilidades. $\mathrm{O}$ horário de almoço, por exemplo, que deveria ser um tempo de descanso e / ou recreação, é passado em sala de aula por falta de espaço e profissionais que possibilitem a oferta de outras opções de atividade fora dela. O próprio almoço é servido em sala de aula para os alunos de nove anos acima, pois não há lugar para todos no refeitório. Assim, não é possível escolher quando não há opções de escolha.

Enfatizando o exposto, temos a fala da professora pedagoga acerca desse tópico de discussão:

As crianças ficam muito tempo presas em sala, mesmo o tempinho que elas têm vago, sem aula, elas estão presas na sala porque não tem onde colocar essas crianças. Elas não têm um tempo pra elas fazerem o que elas quiserem livremente. Os banheiros são precários. A proposta é boa, porém a estrutura não ajuda. É tudo em sala. Jogos na sala, televisão na sala, aula na sala, almoçar na sala. Então é muito preso. No horário livre deles, eles estão em sala fazendo uma atividade dirigida. Então, na prática, não existe horário livre (Pedagoga).

Educação \& Realidade, Porto Alegre, v. 40, n. 1, p. 229-251, jan./mar. 2015. 
Outro tema recorrente na fala das participantes diz respeito à precariedade estrutural da escola. Todas foram unânimes em ressaltar que o prédio atual é inadequado e não atende às novas demandas de funcionamento da instituição.

A escola teve dificuldades e continua tendo, principalmente na questão física, estrutural, ela não é uma escola preparada, pensada, planejada para ser de tempo integral. Ela seria uma escola razoável para o ensino regular, não para tempo integral. Demanda investimento, ampliação. A proposta é nova até para a própria prefeitura (Diretora).

Eu acho a proposta excelente. Pena que não temos estrutura, nem profissionais disponíveis para termos todas essas oficinas ao mesmo tempo na escola. A cada ano perdemos uma, acrescentamos outra, trocamos uma por outra para adequar o espaço da escola e a disponibilidade do profissional (Coordenadora pedagógica).

Na minha opinião, a escola não oferece ainda uma educação integral ao aluno justamente por causa desse ponto aí que é a estrutura da escola (Pedagoga)

[...] infelizmente a estrutura e falta de profissional, falta assim, não é falta, tem que ter mais profissionais... Então aí não dá pra ter essa educação integral (Professora de Educação Física).

Borges compartilha com a opinião da pedagoga: "Ninguém aguenta ficar na sala de aula 7 horas por dia. Há que se ter espaço para circulação de professores e alunos" (Borges, 2012, comunicação verbal). Ou seja, há que se ter espaço adequado para as demandas de qualquer escola, inclusive para as especificidades do funcionamento da escola de tempo integral. Sobre essa questão, o Programa para as Escolas Municipais com Atendimento em Tempo Integral assim se posiciona:

Hoje uma das fragilidades das escolas em tempo integral, provavelmente a maior delas, é a estrutura física. Entendendo que a estrutura física adequada é um dos fatores determinantes para a qualidade do ensino aprendizagem nas escolas em tempo integral, é fundamental que as mesmas possuam uma estrutura básica para o sucesso do trabalho desenvolvido. Toda escola em tempo integral precisa de: refeitório, área de convivência, quadra coberta, laboratório de informática, laboratório de ciências, salas de leitura, salas ambientes amplas (multiuso) e baterias de sanitários e chuveiros (Borges, 2009, p. 21).

A escola pesquisada não reflete as deliberações do documento, como as participantes deixaram bem claro. A resolução existe, foi elaborada pela Secretaria Municipal de Educação, mas não é cumprida pelo poder público municipal. Um contrassenso corroborado pela coordenadora pedagógica da escola: 
Depois que nós viramos escola de tempo integral, a única coisa que eles fizeram foi trocar o telhado. E até hoje nós vivemos da promessa da prefeitura de reformar a escola, adaptando ela para o tempo integral. A nossa estrutura tá na base do improviso. Todo ano eles prometem, mas até agora nada (Coordenadora pedagógica).

No próximo excerto, a diretora traz uma reflexão interessante acerca da função, ou melhor, das funções da escola de tempo integral.

A visão de escola de tempo integral, a questão de que o aluno aquela família não dá conta. Então o Conselho Tutelar, Ministério Público tem a visão de que uma escola de tempo integral oferece atendimento pro aluno durante o dia, principalmente no horário que a família tá trabalhando, afastando ele das ruas. Então tá preocupado com a questão do aluno na condição de ficar solto, não ter uma pessoa pra olhar. E a preocupação nossa, além de manter esse aluno aqui, é a questão da aprendizagem (diretora).

\begin{tabular}{|c|c|c|}
\hline $\begin{array}{c}\text { Included Terms } \\
\text { (termos incluídos) }\end{array}$ & $\begin{array}{c}\text { Semantic Relationship } \\
\text { (relação semântica) }\end{array}$ & $\begin{array}{c}\text { Cover Terms } \\
\text { (termo geral) }\end{array}$ \\
\hline$X$ & éfunção de & $Y$ \\
\hline$\bullet \begin{array}{l}\text { Manter o aluno } \\
\text { na escola } \\
\text { - Afastar o aluno } \\
\text { das ruas } \\
\text { Cuidar do } \\
\text { aluno } \\
\text { Oferecer } \\
\text { atendimento ao } \\
\text { aluno durante } \\
\text { o dia }\end{array}$ & são funções da & Escola de tempo integral \\
\hline
\end{tabular}

A Modernidade trouxe consigo inovações políticas, sociais e tecnológicas. A escola, por conseguinte, apesar de não acompanhar esses avanços com a mesma velocidade, não está desvinculada dessas inovações, visto que a mesma é uma instituição social. Esta sempre esteve a serviço da sociedade, acumulando funções, para as quais nem sempre está preparada. Portanto, não é novidade para os profissionais que lidam com a educação o fato de que a escola vem ampliando cada vez mais sua função para além do ato de ensinar e instruir. A fala da diretora deixa isso muito claro.

Há, pois, a preocupação da sociedade civil, Ministério Público, Conselho Tutelar, governos, família em manter o aluno na escola e, assim, poupá-lo da violência das ruas. A função do Estado de combater a violência através de políticas de segurança pública passou para a escola, pois ela mantem esse aluno seguro ${ }^{7}$. Ademais, na escola esse aluno recebe cuidados, visto que esta o atende em suas necessidades mais básicas de alimentação, higiene, saúde - funções da família e do Estado. Enfim, a escola tem tantas obrigações para com o aluno que a aprendizagem fica em segundo, ou quem sabe terceiro plano. Afinal, na escola, principalmente na de tempo integral, o aluno não está solto. 
Educação Integral e Escola de Tempo Integral em Goiânia

Ao contrário, está preso com outros alunos e com professores que estão se esforçando para exercer as funções de professor, educador, família, psiquiatra, médico, agente carcerário (dos menores infratores que, por determinação do Ministério Público, cumprem suas medidas socioeducativas na escola de tempo integral), dentre outras.

Dessa forma, acreditamos que, para que a escola desempenhe a gama de funções a ela atribuída, necessário seria aumentar o número de profissionais e capacitar a todos para lidar com os novos encargos da profissão. Ademais, condições deveriam ser oferecidas às instituições para atender adequadamente a esse aluno que tanto precisa. Infelizmente, pela fala angustiada da diretora, percebemos que as funções são deliberadas, mas o auxílio para que as mesmas sejam desempenhadas não vem dos órgãos públicos responsáveis pelo atendimento e, em última instância, pela educação dessas crianças e adolescentes.

Adiante veremos, através da fala de nossas participantes, o descaso da maioria dos pais com a educação de seus filhos. Aparentemente, a escola tornou-se sinônimo de lugar onde se deixa o filho ao invés de lugar onde o filho recebe instrução, conhecimento, onde ele aprende a pensar, refletir, questionar e ser capaz de atuar no mundo em que vive. A escola, principalmente a de tempo integral, para muitos, funciona como creche, onde os professores não passam de cuidadores que atendem seus alunos em suas necessidades mais básicas, inclusive de educação. Vejamos os excetos e a opinião de alguns autores acerca dessa questão:

Eu acho a proposta excelente. O pai fica tranquilo. Essa é a parte negativa porque o pai fica tão tranquilo que some da escola. Tem muito pai que nos encara como se a gente fosse CEMEI (creche). Pai só vem pra reclamar de alguma coisa, pra saber como vai o desenvolvimento do aluno, não vem (Coordenadora pedagógica).

A participação da família é muito pouca. Nós já acostumamos a resolver as coisas aqui entre nós mesmo. Você liga pro pai ou pra mãe eles sempre tem uma desculpa pra não comparecer. A gente tenta resolver sem incomodar os pais. Quando não tem outro jeito, a gente liga assim mesmo e tem mãe que acha que a gente tá incomodando que é a gente que tem que resolver mesmo (Pedagoga).

A quantidade de aluno é muito grande. É outro ponto negativo. Temos alunos aqui até da Vila Mutirão. O pai quer por o filho aqui para ele trabalhar e ficar tranquilo. É um lugar para deixar o filho. A escola é muito lotada, não tem espaço. Isso dificulta muito o trabalho do professor (Coordenadora Pedagógica). 


\begin{tabular}{|c|c|c|}
\hline $\begin{array}{c}\text { Included Terms } \\
\text { (termos incluídos) }\end{array}$ & $\begin{array}{c}\text { Semantic Relationship } \\
\text { (relação semântica) }\end{array}$ & $\begin{array}{c}\text { Cover Terms } \\
\text { (termo geral) }\end{array}$ \\
\hline$X$ & é um lugar de & $Y$ \\
\hline$\bullet \begin{array}{c}\text { A escola de } \\
\text { tempo integral }\end{array}$ & é um lugar de & deixar o filho \\
\hline
\end{tabular}

Libâneo (2012) pontua que a escola pública de tempo integral tem a finalidade prioritária de suprir as necessidades sociais imediatas, as quais deveriam ser, a priori, de total responsabilidade do Estado. $\mathrm{O}$ autor vai além fazendo uma contraposição entre a escola pública e a escola particular de tempo integral: a primeira é a escola do acolhimento, integração, do assistencialismo social, onde se prioriza o cuidar (alimentar, noções de higiene, proteção, etc.); a segunda é a escola da formação cultural e científica, onde se prioriza o conhecimento.

Para Gadotti “[...] a escola não pode fazer tudo o que a sociedade não está fazendo; ela não pode substituir todas as políticas sociais” (Gadotti, 2009, p. 30). Borges (2012) salienta que a escola de tempo integral não deve ser um lugar para deixar a criança porque a rua é um risco. A autora compartilha com Paro (1988) a ideia de que o papel da escola é prioritariamente pedagógico e que outras funções podem coexistir desde que não interfiram, prejudiquem ou impossibilitem o cumprimento da função primeira da escola: a pedagógica.

Apesar de tentar cumprir com essas duas funções, cuidar e instruir, percebemos, pelo domínio cultural gerado através da fala da diretora, que atender ao aluno em suas necessidades básicas de segurança, alimentação e higiene está em primeiro plano na instituição, seguido de perto, obviamente, pela preocupação didático-pedagógica. Apesar disso, a diretora mostra-se bastante preocupada em conciliar a função imposta pelo Estado e pela sociedade com a função que lhe é atribuída enquanto responsável por essa instituição de ensino: proporcionar o conhecimento, a aprendizagem desses alunos.

\section{Considerações Finais}

Através da discussão e interpretação dos dados apresentados, foi possível perceber que a ideia de educação integral ainda é um tanto abstrata para as participantes. Essa educação é algo que se pretende alcançar, mas depende de mais profissionais, de estrutura adequada, de profissionais comprometidos. Aparentemente, a educação integral está intimamente ligada ao fato de a escola funcionar em tempo integral. O que, como discutido anteriormente, não é uma máxima necessariamente verdadeira. Educação integral envolve comprometimento da equipe docente, e a organização em tempo integral exige um mínimo de estrutura física que possibilite o ensino e a aprendizagem. $O$ intento é que um complemente o outro em prol de uma educação de qualidade que produza resultados profícuos.

Educação \& Realidade, Porto Alegre, v. 40, n. 1, p. 229-251, jan./mar. 2015.

Disponível em: <http://www.ufrgs.br/edu_realidade> 
Educação Integral e Escola de Tempo Integral em Goiânia

Percebemos, também, que a educação integral se perde no fato de que a escola precisa atender ao aluno em suas necessidades básicas de segurança, saúde, higiene, etc. Necessidades estas que deveriam ser compartilhadas de maneira igualitária entre as três instituições responsáveis pela formação do cidadão: o Estado, a família e a escola. Indo ao encontro do que advoga Libâneo (2012) sobre a escola do acolhimento, a escola de tempo integral, nesse contexto, funciona como um abrigo para crianças em situação de risco ou para aquelas que não têm com quem ficar para que os pais possam trabalhar. Diante disso, a educação integral, que deveria ser a premissa primeira, é apenas mais uma meta a ser atingida.

Ademais, pudemos perceber que a prática é bem diferente do que preconizam os documentos oficiais sobre a educação integral em tempo integral. A transição, de certa forma, traumática vivida pelos profissionais da escola foco deste estudo é um bom exemplo disso. Não houve planejamento adequado, preparação devida de pessoal nem de estrutura física para que a escola deixasse o tempo parcial e passasse a atender todas as demandas do tempo integral. Além disso, as adequações preconizadas no documento da Secretaria Municipal de Educação nunca chegaram. A escola vive e sobrevive integralmente no improviso, penalizando a todos pela sua estrutura física insuficiente, pelo número insuficiente de profissionais, pelo número exagerado de crianças por sala, pelos mandos e desmandos da Justiça, do Conselho Tutelar, do Ministério Público e da Secretaria Municipal de Educação.

Obviamente, tantas demandas, com tão pouca assistência por parte dos órgãos públicos municipais, são impossíveis de serem atendidas a contento. Assim, a educação integral se perde na ideia do tempo integral do acolhimento, do atendimento e da reabilitação de menores infratores. A fala da diretora da escola deixa claro sua preocupação em assumir, enquanto gestora da instituição, todas as funções impostas. Em meio a tantas obrigações, ensinar integralmente fica para quando e se for possível, afinal atender, acolher, cuidar do aluno e oferecer tranquilidade aos pais para que estes possam trabalhar é função da escola de tempo integral no contexto vivenciado pelas participantes da pesquisa.

Constatamos também que não foi oferecida a formação necessária acerca dos pressupostos teóricos que embasam a ideia de educação integral em tempo integral. Segundo as participantes, faltou o preparo, o estudo que, a nosso ver, deveria ter sido iniciado pelo menos seis meses antes do período de transição do tempo parcial para o tempo integral. Isso tornaria o processo mais tranquilo e seguro para todos. Mesmo depois da transição, improvisação e árdua adequação, não houve uma iniciativa efetiva de formação que contemplasse todos os funcionários da escola, igualmente importantes em suas funções específicas.

Enfim, pudemos perceber o empenho e a dedicação das participantes, apesar de todas as dificuldades enfrentadas. Acreditamos, pois, 
que o melhor, dentro do possível, está sendo feito. Valendo-se dos anos de experiência, do conhecimento adquirido pela formação inicial, pois aparentemente não há formação continuada, e até mesmo da intuição, todas tentam, dentro de suas áreas de atuação, darem o melhor de si para cumprir com as novas demandas que se apresentam, procurando também cumprir a função pedagógica para a qual foram formadas.

Apesar dos problemas, consideramos que a implantação do tempo integral, pautado na educação integral, constitui-se de um avanço na tentativa de melhorar a qualidade do ensino no Brasil. Contudo, os paradigmas impostos para que esta educação se realize estão equivocados. Corroborando e compartilhando com Borges (2012) e Paro (1988), o papel da escola é prioritariamente pedagógico. Outras funções podem coexistir desde que não interfiram, prejudiquem ou impossibilitem o cumprimento da função primeira da escola: a pedagógica. Ademais, a escola de tempo integral não deve ser um lugar para deixar a criança porque a rua é um risco, mas sim porque essa criança precisa ter acesso ao conhecimento científico e cultural acumulado pela humanidade, desenvolver suas potencialidades e ser devidamente preparada para atuar na sociedade, ciente dos seus direitos, deveres e das regras que permitem a convivência social.

Esse trabalho nos permitiu conhecer a realidade de uma das escolas de tempo integral que compõem a Rede Municipal de Ensino de Goiânia. O Programa para as Escolas Municipais com Atendimento em Tempo Integral (2009) preconizava a existência de quinze instituições de tempo integral no município à época. Atualmente, esse número é maior (vinte e duas) até pelas demandas sociais discutidas anteriormente. Tivemos acesso, portanto, a apenas um contexto, por isso mesmo não pretendemos encerrar a discussão sobre educação integral e escola de tempo integral no município de Goiânia. Sabemos que escolas-modelo foram construídas para que essa ideia fosse colocada em prática de maneira mais eficaz. Essa eficácia pode e deve ser o mote para estudos futuros, os quais, esperamos, descrevam um contexto mais profícuo e propício à efetiva educação integral dos educandos.

Recebido em 30 de maio de 2013 Aprovado em 05 de novembro de 2014

\section{Notas}

1 Sigla correspondente a Secretaria Municipal de Educação.

2 Segundo o Departamento Pedagógico da Secretaria Municipal de Educação (2013), atualmente há vinte e duas escolas públicas de ensino fundamental no município de Goiânia, num universo de 163 instituições de ensino.

3 Considerações tecidas durante a palestra, O processo educativo na escola de tempo integral: ensino e aprendizagem em diferentes tempose espaços, como parte da programação do II ENCONTRO REGIONAL SOBRE EDUCAÇÃO INTEGRALE ESCOLA PÚBLICA DE TEMPO INTEGRAL, realizado pela Secretaria Municipal

Educação \& Realidade, Porto Alegre, v. 40, n. 1, p. 229-251, jan./mar. 2015.

Disponível em: <http://www.ufrgs.br/edu_realidade> 
Educação Integral e Escola de Tempo Integral em Goiânia

de Ensino de Aparecida de Goiânia, nos dias 26, 27 e 28 de setembro de 2012, na cidade de Aparecida de Goiânia, Goiás.

4 The method is not that of objectivity, but of disciplined subjectivity.

5 Mason (1997, p.36), por exemplo, prefere falar de gerar dados, ao invés de coletar dados, porque a pesquisa qualitativa rejeita a ideia de que o pesquisador pode ser um coletor de informações completamente neutro sobre o mundo social. Ao contrário, ele é visto como alguém que constrói ativamente o conhecimento sobre o mundo de acordo com certos princípios e métodos que derivam de sua postura epistemológica (Rees; Mello, 2011, p. 34).

6 Considerações tecidas durante a palestra, O currículo na escola de tempo integral, como parte da programação do II ENCONTRO REGIONAL SOBRE EDUCAÇÃO INTEGRAL E ESCOLA PÚBLICA DE TEMPO INTEGRAL, realizado pela Secretaria Municipal de Ensino de Aparecida de Goiânia, nos dias 26, 27 e 28 de setembro de 2012, na cidade de Aparecida de Goiânia, Goiás.

7 Acreditamos que a escola já não consegue mais manter seus alunos dentro dela. Fugas e faltas são constantes. A escola também não é mais um ambiente seguro, visto que ela é reflexo da sociedade violenta em que vivemos. Não raro notícias de bombas, brigas, homicídios, agressões físicas chegam até nós.

\section{Referências}

ANDRÉ, Marli Elisa Dalmazo Afonso de. Etnografia da prática escolar. Campinas, SP: Papirus, $12^{\text {a }}$ edição, 2005.

BORGES, Lívia Freitas Fonseca. Palestra - o currículo na escola de tempo integral. II Encontro Regional sobre Educação Integral e Escola Pública de Tempo Integral. Secretaria Municipal de Educação de Aparecida de Goiânia, de 26 a 28 de setembro, 2012.

BRASIL. Constituição Federal. Diário Oficial [da] República Federativa do Brasil, Poder Executivo, Brasília, DF, 1988.

BRASIL. Lei no 8.069 de 13 de julho de 1990. Diário Oficial [da] República Federativa do Brasil, Poder Executivo, Brasília, DF, 1990.

BRASIL. Lei no 9.394, de 20 de dezembro de 1996. Diário Oficial [da] República Federativa do Brasil, Poder Executivo, Brasília, DF, 1996.

BRASIL. Plano Nacional de Educação. PNE / Ministério da Educação. Brasília: Inep, 2001

BRASIL. Ministério da Educação. Proposta Pedagógica Educação integral. In: Salto para o Futuro. TV Escola. Secretaria de Educação a Distância. Ano XVIII, boletim 13, Agosto de 2008.

ERICKSON, Frederick. What Makes School Ethnography 'Ethnographic'? Anthropology and Education Quarterly, Arlington, Spring, v. 15, p. 51-66, 1984.

FREITAS, Cezar Ricardo; GALTER, Maria Inalva. Reflexões sobre a Educação em Tempo Integral no Decorrer do Século XXI. Revista de Educação, Cascavel, v. 2, n.3, p. 123 - 138, jan./jun. 2007.

GADOTTI, Moacir. Educação Integral no Brasil: inovações em processo. São Paulo: Editora e Livraria Instituto Paulo Freire, 2009. - (Educação Cidadã; 4).

GIOLO, Jaime. Educação de Tempo Integral: resgatando elementos históricos e conceituais para o debate. IN: MOLL, Jaqueline et al. Caminhos da Educação 
Integral no Brasil: direito a outros tempos e espaços educativos. Porto Alegre: Penso, 2012. P. 94-105.

GOIÂNIA. Secretaria Municipal de Educação de Goiânia (SME). Programa para as escolas com atendimento em tempo integral (versão preliminar), 2009.

GOIÂNIA. Secretaria Municipal de Educação de Goiânia (SME). Ofício no 147/2013 - Departamento Pedagógico (DEPE). 25 de junho de 2013.

LIBÂNEO, José Carlos. Palestra - o Processo Educativo na Escola de Tempo Integral: ensino e aprendizagem em diferentes tempos e espaços. II Encontro Regional Sobre Educação Integral e Escola Pública de Tempo Integral. Secretaria Municipal de Educação Aparecida de Goiânia, de 26 a 28 de setembro, 2012.

MASON, Jennifer. Qualitative researching. London: SAGE Publications, 1997.

MORIN, Edgar. A Cabeça Bem-Feita, Repensar a Reforma, Reformar o Pensamento. 5. Ed. Rio de Janeiro: Bertrand do Brasil, 2001.

PARO, Vitor Henrique et al. A Escola Pública de Tempo Integral: universalização do ensino e problemas sociais. Cadernos de Pesquisa, São Paulo, n. 65, p. 11-20, 1988.

PARO, Vitor Henrique. Viabilidade da Escola Pública em Tempo Integral. Educação e Sociedade, Campinas, n. 29, p. 86-99, 1988.

REES, Dilys Karen; MELLO, Heloísa Augusta Brito de. A Investigação Etnográfica na Sala de Aula de Segunda Língua/ Língua Estrangeira. Cadernos do IL, Porto Alegre, n. 42, p. 30-50, jun. 2011.

SPRADLEY, James. Participant Observation. Fort Worth: Harcourt Brace College Publishers, 1980.

TEIXEIRA, Anísio. Uma experiência de Educação Primária Integral no Brasil. Revista Brasileira de Estudos Pedagógicos, Rio de Janeiro, vol. 38, nº 87, p. 2133, jul./set., 1962.

WATSON-GEGEO, Karen Ann. A Etnografia na Sala de Aula de Segunda Língua: definindo o que é essencial. Tradução por Heloísa Augusta Brito de Mello e Dilys Karen Rees. Signótica, Goiânia, v. 22, n. 2, p. 515-539, 2010.

Helen Betane Ferreira é professora de Língua Inglesa de uma escola de tempo integral da Rede Municipal de Ensino (RME) de Goiânia. Doutoranda em Estudos Linguísticos pelo Programa de Pós-Graduação em Letras e Linguística da Faculdade de Letras da Universidade Federal de Goiás.

E-mail: helen.betane@yahoo.com.br

Dilys Karen Rees é professora adjunta nível 3 da Universidade Federal de Goiás (UFG). Professora do Programa de Pós-Graduação em Letras e Linguística da Faculdade de Letras da Universidade Federal de Goiás e orientadora da primeira autora.

E-mail: dilys_br@yahoo.com 